\title{
Locally advanced renal cell carcinoma
}

\author{
Mohammed Al Otaibi, MD; Simon Tanguay, MD
}

\begin{abstract}
Despite the observed stage migration and earlier detection of renal masses, patients still present with locally advanced renal cell carcinoma. These patients represent a difficult oncologic challenge. Despite our ability to do surgical resection to cure the disease, survival often remains limited. In this paper, we describe the role and indication for surgical resection for patients with enlarged retroperitoneal lymph nodes, invasion of adjacent organs, invasion into the vena cava or locally recurrent disease. The development of new strategies, including effective drugs to be used in association with surgical resection, will clearly be an essential step to further improve the outcome of these patients.
\end{abstract}

\footnotetext{
$\mathrm{R}$
} enal cell carcinoma (RCC), one of the most lethal urologic cancers, accounts for $3 \%$ of all adult malignancies, and more than $40 \%$ of patients with RCC will die of their disease. ${ }^{1,2}$ Surgery remains the most curative treatment option for patients with localized RCC. Pathological stage, tumour grade and lymph-node status are independent predictors of progression-free and overall survival in patients with RCC., ${ }^{3,4}$ Patients with low-stage and low-grade RCC tend to have a more favourable outcome than patients presenting with metastatic disease. This finding remains true, despite the use of a combination of aggressive surgical resection and immunotherapy or, more recently, targeted therapy. ${ }^{3-9}$ Patients with locally advanced RCC also have a significant risk of disease recurrence and progression, despite complete surgical resection. Included in this category of locally advanced RCC are patients with inferior vena cava (IVC) involvement, extension to adjacent organs (stage T4) retroperitoneal lymph-node involvement and local recurrence after radical surgery. In this paper, we review the outcome of patients with locally advanced RCC and the role of surgery in these challenging patients.

\section{IVC involvement}

Tumour thrombus extending into the IVC occurs in $4 \%-10 \%$ of patients with RCC..$^{10}$ Aggressive surgical resection with radical nephrectomy and IVC thrombectomy can potentially cure up to $70 \%$ of these patients (Table 1). ${ }^{11-16}$

A number of pathological factors help predict the outcomes of patients with RCC and IVC thrombus. Tumour confined to the kidney and freefloating tumour thrombus have good prognoses, whereas perinephric fat invasion, lymph-node involvement and caval-wall invasion are associated with a poor prognosis. ${ }^{17-23}$

For many years, the level of tumour thrombus extension was associated with the prognosis of patients with pT3b RCC. Although this factor may play an indirect role in reflecting the local extent of the tumour, local extension, more than thrombus length, predicts postoperative recurrence. Sweeney and colleagues ${ }^{24}$ demonstrated the impact of local extension with invasion of perinephric fat on patients with pT3b RCC. In their review, the median survival of patients with IVC involvement decreased from 33 months to 10 months if they had perinephric fat invasion. Similar findings were reported by both Ficarra and Artibani $^{25}$ and Thompson and colleagues ${ }^{26}$ who concluded that perinephric fat invasion had an independent prognostic impact on the cancer-specific survival of patients with IVC involvement. This factor seems to have a greater impact on disease-specific survival than the level of IVC thrombus. Both authors proposed that stage pT3 RCC be reclassified to include invasion of perinephric fat as an independent factor and that this be incorporated in the pT3 TNM staging system so that patients could be better stratified, relative to their real risk for recurrence of the disease.

The prognostic significance of the cephalad extent of the IVC thrombus has been a source of controversy. Most series suggest that the incidence of either local or systemic progression is higher in patients with level III or level IV IVC thrombus. Many authors ${ }^{13,14,23,27,28}$ associated this finding with reduced survival. Other reports, ${ }^{19,24}$ however, suggest that patients with level IV IVC thrombus can be cured with surgical resection, provided that the tumour is otherwise confined to the kidney. 
Surgical planning remains an integral and important part of the management of RCC with IVC involvement. Accurate staging of the extent of IVC thrombus is essential to properly plan the surgical approach (Fig. 1). Therefore, imaging plays a crucial role. Traditionally, a CT scan was used to diagnose renal vein and IVC thrombus, but a CT scan was often limited in its ability to accurately define the cephalad extent of the thrombus. ${ }^{29}$ Transesophageal echocardiography, transabdominal colour flow Doppler ultrasonography or cavography have been used as complementary imaging modalities, when needed, to define the exact extent of renal vein or IVC involvement. ${ }^{30} \mathrm{MRI}$ is an accurate diagnostic tool for the delineation of the cephalad extent of the tumour thrombus; ${ }^{29,31}$ however, recent data ${ }^{32-35}$ suggest that multiplanar CT scan may approach the accuracy of MRI for identification and characterization of IVC thrombus. Although contrast venography is highly accurate, its invasive nature precludes its use; it is now reserved for the rare cases in which MRI or a CT scan would be contraindicated or equivocal.

Table 1. Five-year survival for patients with RCC and IVC thrombus

\begin{tabular}{lccc}
\hline Authors (and date) & $\begin{array}{c}\text { No. of } \\
\text { patients }\end{array}$ & M0, \% & M1, \% \\
\hline Novick et al ${ }^{11 *}(1990)$ & 43 & 64 & 11 \\
Swierzewski et al ${ }^{12}(1994)$ & 100 & 64 & 20 \\
Quek et $\mathrm{al}^{13}(2001)$ & 99 & 59 & 0 \\
Zisman et $\mathrm{al}^{14}$ (2003) & 100 & 72 & N/A \\
Blute et $\mathrm{al}^{15}(2004)$ & 191 & 59 & 15 \\
\hline
\end{tabular}

$\mathrm{RCC}=$ renal cell carcinoma; IVC = inferior vena cava; $\mathrm{MO}=$ no metastasis; $\mathrm{M} 1=$ distant metastasis; N/A = not available.

*3-year survival.

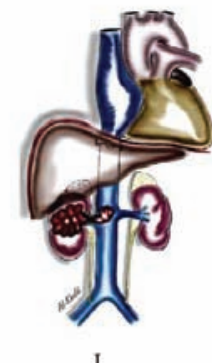

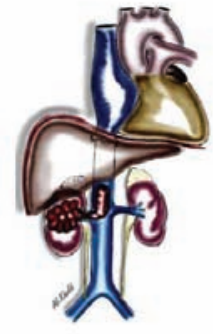

II

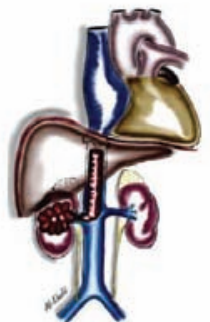

III

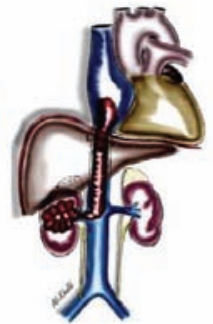

IV
Fig. 1. Clinical staging of tumour thrombus.
The surgical approach to patients with IVC involvement is mostly dictated by the cephalad extent of the thrombus. The choice of incision (midline, subcostal or chevron) remains the preference of the individual surgeon. Surgical techniques include mobilization of the kidney and early ligation of the arterial blood supply to the kidney. This initial manoeuvre often results in a reduction of the size of the tumour thrombus, facilitating the rest of the surgery. To properly control the involved portion of the IVC for patients with level I and II thrombus, ligation of all lumbar veins, followed by sequential clamping of the caudal IVC, contralateral renal vein and cephalad IVC, is required. The renal vein ostium is then opened and excised to extract, en bloc, the tumour thrombus. For patients with level III caval thrombus, mobilization of the caudate lobe of the liver allows exposure and access to the intrahepatic IVC. This manoeuvre provides access to the cephalad extent of the thrombus and allows the surgeon to safely clamp the IVC below the hepatic veins. ${ }^{36}$ If the thrombus extends above the hepatic veins and below the diaphragm, a liver transplant technique with complete liver mobilization, as described by Ciancio and others, ${ }^{37}$ will safely expose the hepatic veins. This manoeuvre facilitates mobilization and exposure of the entire infradiaphragmatic IVC and allows safe excision of more extensive tumour thrombus. A Pringle manoeuvre and selective occlusion of the hepatic veins may be necessary, with control of the IVC above the liver. ${ }^{38-42}$

In patients with level IV tumour thrombus, cardiopulmonary bypass with or without hypothermic circulatory arrest has been used to facilitate excision of the tumour thrombus. This approach allows safe excision of extensive tumour thrombus, but is associated with increased risk of coagulopathy, cerebrovascular accidents and myocardial infarction. ${ }^{43-47}$

Preoperative renal angiography and embolization is practised in some centres when tumour thrombus shows distinct vascularity. This approach often reduces the size of the tumour thrombus and venous pressure within the kidney and tumour, and may facilitate surgical excision of the renal tumour and thrombus. ${ }^{11,24}$ This approach will occasionally reduce the size of the tumour thrombus from level III to II, or from level IV to III. This reduction can therefore facilitate tumour resection and may limit surgical morbidity. 
In cases in which the tumour thrombus invades the wall of the vena cava, aggressive resection of the caval wall to achieve negative surgical margins is necessary to avoid local recurrence and improve survival. ${ }^{17}$ When complete occlusion with absence of flow in the IVC is present before surgery, en bloc resection with ligation of the IVC may facilitate complete tumour excision and limit the chance of leaving residual disease in areas with unrecognized tumour invasion into the wall of the vena cava. IVC grafting or reconstruction may be required in some cases to avoid partial caval occlusion after extended resection of part of the IVC. ${ }^{48}$ Radical nephrectomy with IVC thrombectomy, however, remains a morbid procedure; since operative mortality rates are $5 \%-10 \%$, patients must be carefully selected for this procedure. . $15,16,49^{2}$

\section{Locally invasive RCC (T4 disease)}

On rare occasions, RCC occurs with direct invasion into adjacent organs (T4 disease). Liver, spleen, colon, pancreas, diaphragm and duodenum are usually compressed by the RCC and rarely invaded because these tumours are often encapsulated. Invasion of adjacent organs is usually associated with poor prognosis. Pain often occurs when the RCC invades the posterior abdominal wall or nerve roots. The poor prognosis associated with pT4 disease is also frequently associated with nodal and systemic metastasis, a higher Fuhrman nuclear grade or sarcomatoid differentiation. ${ }^{26}$ In fact, Lam and colleagues, ${ }^{50}$ using the University of California Los Angeles integrated staging system, or UISS, classified T4 RCC in their high-risk group, with a median time to recurrence of only 9.5 months, regardless of grade or performance status. These reports reinforce the clinical behaviour of these advanced cancers that generally have a poor prognosis and require close follow-up for timely treatment.

An aggressive surgical approach with en bloc resection of involved adjacent organs is the only potentially curative treatment. Nearly $90 \%$ of patients with pT4 RCC died of disease progression within 1 year if they were treated with incomplete resection or debulking. ${ }^{51}$ However, understanding of the biology and natural history of these locally advanced cancers is based on a very limited number of small retrospective series ${ }^{26,52}$ of patients with T4 disease. These clinical series ${ }^{26,52}$ described a limited 5\%-18\% 5-year survival.
The role of radiation therapy for locally invasive RCC remains unclear. Stein and others ${ }^{53}$ suggested that adjuvant radiotherapy was beneficial. However, subsequent studies ${ }^{54,55}$ that randomized patients with locally advanced RCC to either adjuvant radiotherapy or observation have shown no survival benefit of adjuvant radiotherapy and potential nonnegligible gastrointestinal morbidity. Obviously, an effective adjuvant treatment strategy is required for this patient population. So far adjuvant cytokine therapy has failed to demonstrate a benefit. New studies are being done to evaluate the potential benefit of tyrosine-kinase inhibitors as an adjuvant therapy for this highrisk patient population. Until an effective treatment strategy with survival benefit is identified, early diagnosis with aggressive and complete surgical resection remains the best therapeutic option for these patients.

\section{Regional lymph-node dissection}

Regional lymph-node metastasis in patients with RCC is associated with a poor prognosis and decreased survival. ${ }^{56}$ Unlike some other genitourinary cancers, the lymphatic drainage of the kidneys is not accurately defined. Debate about the potential benefits of routine regional and extended lymph-node dissection continues. In recent years, lymph-node dissection for urologic cancers has been revisited; many centres are now proposing more extensive dissection for diseases such as bladder cancer to improve cancer control. ${ }^{57,58}$ Urologists are very familiar with the therapeutic benefit of lymph-node dissection for the management of testes and penile cancers. The European Organization for Research and Treatment of Cancer's trial (EORTC 30881$)^{59}$ prospectively examined the impact of routine lymph-node dissection at the time of nephrectomy. Only $3.3 \%$ of patients had unsuspected lymph-node metastasis identified by routine lymph-node dissection. Given the low incidence of nodal metastasis undetected by preoperative imaging studies, the preliminary findings of this trial failed to support the benefit of routine lymphadenectomy at the time of radical nephrectomy. ${ }^{59}$ In a retrospective review, Pantuck and colleagues $^{56}$ also failed to demonstrate a difference in either local or distant recurrence-free survival for patients who underwent routine lymphadenectomy at the time of nephrectomy. 
The ability to further select patients at high risk of nodal metastasis would allow proponents of lymph-node dissection to better identify patients likely to benefit from this approach. Blute and colleagues ${ }^{60}$ identified risk factors that predicted lymphatic involvement in patients with RCC. These factors included the presence of a high Fuhrman grade, sarcomatoid component, histologic tumour necrosis, tumour size larger than $10 \mathrm{~cm}$ and pathological stage T3 or T4 disease. The incidence of lymph-node involvement in their series increased to $10 \%$ if 2 or more of these factors were present, but was only $0.6 \%$ when fewer than 2 factors were identified. Although many reports do not support routine lymph-node dissection, Canfield and others ${ }^{61}$ evaluated 54 patients with $\mathrm{N}+\mathrm{M} 0$ disease and concluded that patients with $\mathrm{N} 1$ disease survived significantly longer than those with N2 disease (median $37.5 \mathrm{mo}$ and $14.5 \mathrm{mo}$, respectively), suggesting a potential benefit of lymph-node dissection in this rare clinical presentation of patients with metastasis to a single lymph node. If hilar lymph nodes are the first level of metastasis, a properly executed radical nephrectomy that includes the hilar and adjacent paracaval or paraaortic lymph nodes could provide a potential curative benefit. Currently, however, the need for routine extended lymphadenectomy for all patients is not justified. ${ }^{59-62}$

Although the role of lymph-node dissection in clinical NO disease remains limited, patients with metastatic disease undergoing cytoreductive nephrectomy may have a different clinical outcome. Pantuck and others ${ }^{56}$ demonstrated a benefit of complete excision of lymph nodes for patients with metastatic disease who were undergoing cytoreductive nephrectomy. This finding reinforces the role and potential clinical benefit of aggressive surgical resection for patients undergoing cytoreductive nephrectomy. At least in this limited clinical presentation, retrospective data support the potential benefit of extended lymph-node dissection to completely remove all retroperitoneal disease.

\section{Local recurrence after treatment of RCC}

Local recurrence of RCC after radical nephrectomy remains a rare event. Published series ${ }^{63-69}$ report that between $2 \%$ and $4 \%$ of patients with RCC will develop a local recurrence after radi- cal nephrectomy. Stephenson and others ${ }^{69}$ reported a $1.6 \%$ incidence of local recurrence among 495 patients who underwent a radical nephrectomy. Of these 495 patients, only $0.6 \%$ had an isolated local recurrence without systemic disease. These findings were similar to those of most reported series ${ }^{63,64,66,67,70}$ in which the majority of patients with local recurrence also had systemic disease at diagnosis; only $40 \%$ of patients had true isolated local recurrences. Few pathological features have been proposed as risk factors that predict an increased risk of local recurrence of the disease. These include increasing $T$ stage or node-positive disease in some, ${ }^{64,65,70}$ but not all, series. Many series $^{71-78}$ clearly identified the presence of locally recurrent disease in all pathological stages.

Not all patients with locally recurrent disease will be symptomatic at presentation. The presence of symptoms leading to the discovery of a local recurrence varies widely from $7 \%$ to $73 \% .{ }^{.7}$ Most authors would agree that a large proportion of patients diagnosed with an isolated local recurrence were detected during routine abdominal imaging. The majority of the published series are limited by small numbers of patients and retrospective analysis; however, Schrodter and others ${ }^{67}$ and Master and others ${ }^{77}$ were able to identify a correlation between the time to recurrence and the likelihood of surviving this disease. In both series, the subset of patients who died had a mean time to recurrence of 16 months, compared with $79^{67}$ and 83 months $^{77}$ for patients who survived. These findings reinforce the well-known heterogeneity of the characteristics of RCC and its clinical behaviour.

Currently, treatment of locally recurrent disease in the absence of systemic disease should be surgical resection. An aggressive surgical resection can provide up to 30\% 5-year disease-free survival. $66,67,71-73,79,80$ However, complete surgical resection with negative surgical margins is crucial and en bloc resection of adjacent organs should be done to achieve this goal. Both Tanguay and oth$\mathrm{ers}^{71}$ and Sandhu and others ${ }^{78}$ confirmed that positive surgical margins indicate a poor prognosis and will negatively influence local and distant disease-free survival. These findings reinforce the importance of proper planning for surgery, during which urologists must be ready to proceed with wide excision and resection of adjacent organs to achieve complete surgical resection of the 
tumour with negative margins. Failing to do so will likely result in recurrent disease and decreased survival. It is not surprising, then, that most published series ${ }^{66,71-73,80}$ report complication rates ranging from $18 \%$ to $47 \%$.

Although many of the published reports support the potential benefit associated with an aggressive surgical approach, the role of either systemic therapy or radiation therapy remains to be defined. So far, most authors ${ }^{79,81,82}$ report that disease control with both treatment modalities used alone is reduced. However, this finding may be the result of the retrospective nature of this reported experience and the bias associated with patient selection and referral for possible surgical resection. Radiation therapy may be of value for palliation of symptomatic local recurrence for patients who are not surgical candidates.

Local recurrence after nephron-sparing surgery for RCC has been reported for $1.4 \%-10 \%$ of patients. ${ }^{83-85}$ The main risk factor is advanced T stage disease. Most local recurrences after partial nephrectomy are likely the result of unrecognized tumour multicentricity or new tumour development, rather than a true failure of treatment. ${ }^{74}$ Patients with an isolated local recurrence after partial nephrectomy should be treated as if they have a new RCC, with either repeated partial nephrectomy, ablative therapies or completion nephrectomy. ${ }^{74-76,83,84}$

\section{Conclusion}

Locally advanced RCC remains a challenge for urologists. However, all the tools developed and our better ability to predict outcomes for our patients can be used to select patients for whom novel therapeutic agents can potentially play a role. Many patients with tumour thrombus extending into the IVC or invasion into adjacent organs are destined to have recurrence of their disease. With the development of new therapeutic targets, adjuvant regimens will likely emerge as viable options for our patients.

The role of regional lymph-node dissection has also been debated over the years. Clearly, in the absence of radiological or clinical enlargement of lymph nodes, routine lymphadenectomy at the time of nephrectomy has no role. Complete lymphadenectomy may have a role in the treatment of patients with limited lymph-node involvement or during cytoreductive nephrectomy. In conclusion, the clinical outcome of patients with locally advanced RCC can be further improved, and combined approaches may offer benefit in the future.

From McGill University Health Centre, Montréal, Que.

This article has been peer reviewed.

Competing interests: None declared.

\section{References}

1. Landis SH, Murray T, Bolden S, et al. Cancer statistics, 1999. CA Cancer J Clin 1999;49: 8-31.

2. Pantuck AJ, Zisman A, Belldegrun AS. The changing natural history of renal cell carcinoma. J Urol 2001;166:1611-23.

3. Zisman A, Pantuck AJ, Wieder J, et al. Risk group assessment and clinical outcome algorithm to predict the natural history of patients with surgically resected renal cell carcinoma. J Clin Oncol 2002;20:4559-66.

4. Leibovich BC, Blute ML, Cheville IC, et al. Prediction of progression after radical nephrectomy for patients with clear cell renal cell carcinoma: a stratification tool for prospective clinical trials. Cancer 2003:97:1663-71.

5. Flanigan RC, Salmon SE, Blumenstein BA, et al. Nephrectomy followed by interferon alfa-2b compared with interferon alfa-2b alone for metastatic renal-cell cancer. N Engl J Med 2001;345:1655-9.

6. Mickisch GH, Garin A, van Poppel H, et al. Radical nephrectomy plus interferon-alfabased immunotherapy compared with interferon alfa alone in metastatic renal-cell carcinoma: a randomised trial. Lancet 2001;358:966-70.

7. Motzer RJ, Mazumdar M, Bacik J, et al. Survival and prognostic stratification of 670 patients with advanced renal cell carcinoma. J Clin Oncol 1999;17:2530-40.

8. Escudier B, Eisen T, Stadler WM, et al. Sorafenib in advanced clear-cell renal-cell carcinoma. N Engl J Med 2007;356:125-34.

9. Motzer RJ, Hutson TE, Tomczak $P$, et al. Sunitinib versus interferon alfa in metastatic renal-cell carcinoma. N Engl J Med 2007;356:115-24.

10. Marshall FF. Renal cell carcinoma: surgical management of regional lymph nodes and inferior vena-caval tumor thrombus. Semin Surg Oncol 1988;4:129-32.

11. Novick AC, Kaye MC. Cosgrove DM, et al. Experience with cardiopulmonary bypass and deep hypothermic circulatory arrest in the management of retroperitoneal tumors with large vena caval thrombi. Ann Surg 1990;212:472-6.

12. Swierzewski DJ, Swierzewski MJ, Libertino JA. Radical nephrectomy in patients with renal cell carcinoma with venous, vena caval, and atrial extension. Am I Surg 1994; 168:205-9

13. Quek ML, Stein JP, Skinner DG. Surgical approaches to venous tumor thrombus. Semin Urol Oncol 2001;19:88-97.

14. Zisman A, Wieder JA, Pantuck AJ, et al. Renal cell carcinoma with tumor thrombus extension: biology, role of nephrectomy and response to immunotherapy. J Urol 2003; 169:909-16.

15. Blute ML, Leibovich BC, Lohse CM, et al. The Mayo Clinic experience with surgical management, complications and outcome for patients with renal cell carcinoma and venous tumour thrombus. BJU Int 2004;94:33-41.

16. Staehler $G$, Brkovic $D$. The role of radical surgery for renal cell carcinoma with extension into the vena cava. J Urol 2000;163:1671-5.

17. Hatcher PA, Anderson EE, Paulson DF, et al. Surgical management and prognosis of renal cell carcinoma invading the vena cava. J Urol 1991;145:20-3.

18. Montie JE, el Ammar R, Pontes JE, et al. Renal cell carcinoma with inferior vena cava tumor thrombi. Surg Gynecol Obstet 1991;173:107-15.

19. Glazer AA, Novick AC. Long-term followup after surgical treatment for renal cell carcinoma extending into the right atrium. J Urol 1996;155:448-50. 
20. Naitoh J, Kaplan A, Dorey F, et al. Metastatic renal cell carcinoma with concurrent inferior vena caval invasion: long-term survival after combination therapy with radical nephrectomy, vena caval thrombectomy and postoperative immunotherapy. J Urol 1999:162:46-50.

21. Bissada NK, Yakout HH, Babanouri A, et al. Long-term experience with management of renal cell carcinoma involving the inferior vena cava. Urology 2003;61:89-92.

22. Moinzadeh A, Libertino JA. Prognostic significance of tumor thrombus level in patients with renal cell carcinoma and venous tumor thrombus extension. Is all $T 3 \mathrm{~b}$ the same? J Urol 2004;171:598-601.

23. Leibovich $\mathrm{BC}$, Cheville $\mathrm{JC}$, Lohse $\mathrm{CM}$, et al. Cancer specific survival for patients with pT3 renal cell carcinoma-can the 2002 primary tumor classification be improved? I Urol 2005; 173:716-9.

24. Sweeney P, Wood CG, Pisters LL, et al. Surgical management of renal cell carcinoma associated with complex inferior vena caval thrombi. Urol Oncol 2003;21:327-33.

25. Ficarra V, Artibani W. Staging system of renal cell carcinoma: current issues. Eur Urol 2006; $49: 223-5$

26. Thompson RH, Cheville JC, Lohse $\mathrm{CM}$, et al. Reclassification of patients with $\mathrm{pT3}$ and pT4 renal cell carcinoma improves prognostic accuracy. Cancer 2005; 104:53-60.

27. Sosa RE, Muecke EC, Vaughan ED Jr, et al. Renal cell carcinoma extending into the inferior vena cava: the prognostic significance of the level of vena caval involvement. J Urol 1984;132:1097-100.

28. Kim HL, Zisman A, Han KR, et al. Prognostic significance of venous thrombus in renal cell carcinoma. Are renal vein and inferior vena cava involvement different? J Urol 2004; 171:588-91.

29. Goldfarb DA, Novick $A C$, Lorig $R$, et al. Magnetic resonance imaging for assessment of vena caval tumor thrombi: a comparative study with venacavography and computerized tomography scanning. J Urol 1990;144:1100-3.

30. Glazer A, Novick AC. Preoperative transesophageal echocardiography for assessment of vena caval tumor thrombi: a comparative study with venacavography and magnetic resonance imaging. Urology 1997;49:32-4.

31. Kallman DA, King BF, Hattery RR, et al. Renal vein and inferior vena cava tumor thrombus in renal cell carcinoma: CT, US, MRI and venacavography. J Comput Assist Tomogr 1992;16:240-7.

32. Pretorius ES, Wickstrom ML, Siegelman ES. MR imaging of renal neoplasms. Magn Reson Imaging Clin N Am 2000;8:813-36.

33. Sohaib SA, Richards PS, Ind T, et al. MR imaging of carcinoma of the vulva. AJR Am J Roentgenol 2002;178:373-7.

34. Ergen FB, Hussain HK, Caoili EM, et al. MRI for preoperative staging of renal cell carcinoma using the 1997 TNM classification: comparison with surgical and pathologic staging. AJR Am J Roentgenol 2004;182:217-25.

35. Hallscheidt PJ, Fink C, Haferkamp A, et al. Preoperative staging of renal cell carcinoma with inferior vena cava thrombus using multidetector CT and MRI: prospective study with histopathological correlation. J Comput Assist Tomogr 2005;29:64-8.

36. Gallucci $M$, Borzomati D, Flammia $G$, et al. Liver harvesting surgical technique for the treatment of retro-hepatic caval thrombosis concomitant to renal cell carcinoma: perioperative and long-term results in 15 patients without mortality. Eur Urol 2004; 45:194-202

37. Ciancio G, Hawke C, Soloway M. The use of liver transplant techniques to aid in the surgical management of urological tumors. J Urol 2000;164:665-72.

38. Burt JD, Bowsher WG, Joyce $G$, et al. The management of renal cell carcinoma with inferior vena-caval involvement. Aust N Z J Surg 1993;63:25-9.

39. Ciancio G, Soloway M. Renal cell carcinoma invading the hepatic veins. Cancer 2001;92:1836-42.

40. Ciancio G, Soloway M. The use of natural veno-venous bypass during surgical treatment of renal cell carcinoma with inferior vena cava thrombus. Am Surg 2002;68:488-90.

41. Vaidya A, Ciancio G, Soloway M. Surgical techniques for treating a renal neoplasm invading the inferior vena cava. J Urol 2003;169:435-44.

42. Jibiki $M$, Iwai $T$, Inove $Y$, et al. Surgical strategy for treating renal cell carcinoma with thrombus extending into the inferior vena cava. J Vasc Surg 2004;39:829-35.

43. Vaislic $C D$, Puel $P$, Grondin $P$, et al. Cancer of the kidney invading the vena cava and heart. Results after 11 years of treatment. I Thorac Cardiovasc Surg 1986;91:604-9
44. Marshall FF, Reitz BA, Diamond DA. A new technique for management of renal cell carcinoma involving the right atrium: hypothermia and cardiac arrest. J Urol 1984;131: 103-7.

45. Stewart JR, Carey JA, McDougal WS, et al. Cavoatrial tumor thrombectomy using cardiopulmonary bypass without circulatory arrest. Ann Thorac Surg 1991;51:717-21.

46. Shinghal R, Vricella LA, Mitchell RS, et al. Cavoatrial tumor thrombus excision without circulatory arrest. Urology 2003;62:138-40.

47. Tasca $A$, Abatangelo $G$, Ferrarese $P$, et al. Experience with an elective vacuum assisted cardiopulmonary bypass in the surgical treatment of renal neoplasms extending into the right atrium. J Urol 2003; 169:75-8.

48. Sarkar R, Eilber FR, Gelabert HA, et al. Prosthetic replacement of the inferior vena cava for malignancy. J Vasc Surg 1998;28:75-81.

49. Gettman MT, Boelter CW, Cheville JC, et al. Charlson co-morbidity index as a predictor of outcome after surgery for renal cell carcinoma with renal vein, vena cava or right atrium extension. J Urol 2003;169:1282-6.

50. Lam JS, Shvarts 0, Leppert JT, et al. Postoperative surveillance protocol for patients with localized and locally advanced renal cell carcinoma based on a validated prognostic nomogram and risk group stratification system. J Urol 2005;174:466-72.

51. Dekernion JB, Ramming KP, Smith RB. The natural history of metastatic renal cell carcinoma: a computer analysis. J Urol 1978;120:148-52.

52. Ficarra V, lafrate M, Cappellaro L, et al. Proposal for reclassification of the TNM staging system in patients with locally advanced (pT3-4) renal cell carcinoma according to the cancer-related outcome. Eur Urol 2007;51:722-9.

53. Stein $M$, Kuten A, Halpern J, et al. The value of postoperative irradiation in renal cell cancer. Radiother Oncol 1992;24:41-4.

54. Gez E, Libes M, Bar-Deroma R, et al. Postoperative irradiation in localized renal cell carcinoma: the Rambam Medical Center experience. Tumori 2002;88:500-2.

55. Kjaer M, Frederiksen PL, Engelholm SA. Postoperative radiotherapy in stage II and III renal adenocarcinoma. A randomized trial by the Copenhagen Renal Cancer Study Group. Int J Radiat Oncol Biol Phys 1987;13:665-72.

56. Pantuck AJ, Zisman A, Dorey F, et al. Renal cell carcinoma with retroperitoneal lymph nodes: role of lymph node dissection. J Urol 2003;169:2076-83.

57. Mills RD, Fleischmann A, Studer UE. Radical cystectomy with an extended pelvic lymphadenectomy: rationale and results. Surg Oncol Clin N Am 2007;16:233-45.

58. Stein JP, Skinner DG. The role of lymphadenectomy in high-grade invasive bladder cancer. Urol Clin North Am 2005:32:187-97.

59. Blom JH, van Poppel H, Marechal JM, et al. Radical nephrectomy with and without lymph node dissection: preliminary results of the EORTC randomized phase III protocol 30881. EORTC Genitourinary Group. Eur Urol 1999;36:570-5.

60. Blute ML, Leibovich BC, Cheville JC, et al. A protocol for performing extended lymph node dissection using primary tumor pathological features for patients treated with radical nephrectomy for clear cell renal cell carcinoma. J Urol 2004;172:465-9.

61. Canfield SE, Kamat AM, Sanchez-Orizz RF, et al. Renal cell carcinoma with nodal metastases in the absence of distant metastatic disease (clinical stage TxN1-2MO): the impact of aggressive surgical resection on patient outcome. J Urol 2006;175:864-9.

62. Phillips $C K$, Taneja $S S$. The role of lymphadenectomy in the surgical management of renal cell carcinoma. Urol Oncol 2004:22:214-23.

63. Uson AC. Tumor recurrence in the renal fossa and/or the abdominal wall after radical nephrectomy for renal cell carcinoma. Prog Clin Biol Res 1982;100:549-60.

64. Sandock DS, Seftel AD, Resnick MI. A new protocol for the followup of renal cell carcinoma based on pathological stage. J Urol 1995;154:28-31.

65. Levy DA, Slaton JW, Swanson DA, et al. Stage specific guidelines for surveillance after radical nephrectomy for local renal cell carcinoma. J Urol 1998;159:1163-7.

66. Itano NB, Blute ML, Spotts B, et al. Outcome of isolated renal cell carcinoma fossa recurrence after nephrectomy. J Urol 2000;164:322-5.

67. Schrodter S, Hakenberg OW, Manseck A, et al. Outcome of surgical treatment of isolated local recurrence after radical nephrectomy for renal cell carcinoma. J Urol 2002; 167:1630-3.

68. Dimarco DS, Lohse CM, Zincke $\mathrm{H}$, et al. Long-term survival of patients with unilateral sporadic multifocal renal cell carcinoma according to histologic subtype compared with patients with solitary tumors after radical nephrectomy. Urology 2004;64:462-7.

69. Stephenson AJ, Chetner MP, Rourke K, et al. Guidelines for the surveillance of localized 
renal cell carcinoma based on the patterns of relapse affer nephrectomy. J Urol 2004; 172:58-62.

70. Phillips E, Messing EM. Role of lymphadenectomy in the treatment of renal cell carcinoma. Urology 1993;41:9-15.

71. Tanguay S, Pisters $L L$, Lawrence DD, et al. Therapy of locally recurrent renal cell carcinoma after nephrectomy. J Urol 1996;155:26-9.

72. Wiesner $C$, Jakse $G$, Rohde D. Therapy of local recurrence of renal cell carcinoma. Oncol Rep 2002;9:189-92.

73. Gogus C, Baltaci S, Beduk Y, et al. Isolated local recurrence of renal cell carcinoma after radical nephrectomy: experience with 10 cases. Urology 2003;61:926-9.

74. Campbell SC, Novick AC. Management of local recurrence following radical nephrectomy or partial nephrectomy. Urol Clin North Am 1994;21:593-9.

75. Gittes RF, Blute RD Jr. Repeat bench surgery on a solitary kidney. J Urol 1982;127:530-2.

76. Moll V, Becht E, Ziegler M. Kidney preserving surgery in renal cell tumors: indications, techniques and results in 152 patients. J Urol 1993;150:319-23.

77. Master VA, Gottschalk AR, Kane C, et al. Management of isolated renal fossa recurrence following radical nephrectomy. J Urol 2005;174:473-7.

78. Sandhu SS, Symes A, A'Hern R, et al. Surgical excision of isolated renal-bed recurrence after radical nephrectomy for renal cell carcinoma. BJU Int 2005;95:522-5.

79. Bruno JJ II, Snyder ME, Motzer RJ, et al. Renal cell carcinoma local recurrences: impact of surgical treatment and concomitant metastasis on survival. BJU Int 2006;97:933-8

80. Esrig D, Ahlering TE, Lieskovsky $G$, et al. Experience with fossa recurrence of renal cell carcinoma. J Urol 1992;147:1491-4.

81. Rabinovitch RA, Zelefsky MJ, Gaynor JJ, et al. Patterns of failure following surgical resection of renal cell carcinoma: implications for adjuvant local and systemic therapy. J Clin Oncol 1994;12:206-12.

82. Finney $R$. The value of radiotherapy in the treatment of hypernephroma $-a$ clinical trial. Br J Urol 1973;45:258-69.

83. Hafez KS, Fergany AF, Novick AC. Nephron sparing surgery for localized renal cell carcinoma: impact of tumor size on patient survival, tumor recurrence and TNM staging. J Urol 1999;162:1930-3.

84. Belldegrun A, Tsui KH, deKernion JB, et al. Efficacy of nephron-sparing surgery for renal cell carcinoma: analysis based on the new 1997 tumor-node-metastasis staging system. J Clin Oncol 1999;17:2868-75.

85. Patard JJ, Kim HL, Lam JS, et al. Use of the University of California Los Angeles integrated staging system to predict survival in renal cell carcinoma: an international multicenter study. J Clin Oncol 2004;22:3316-22.

Correspondence: Dr. Simon Tanguay, McGill University Health Centre, 1650 Cedar, L8-318, Montréal QC H3G 1A4; Simon.Tanguay@mcgill.ca 